Revista Eletrônica de Direito Processual - REDP.

Rio de Janeiro. Ano 11. Volume 18. Número 1. Janeiro a Abril de 2017

Periódico Quadrimestral da Pós-Graduação Stricto Sensu em Direito Processual da UERJ

Patrono: José Carlos Barbosa Moreira. ISSN 1982-7636. pp. 156-173

www.redp.uerj.br

\title{
A CONFIDENCIALIDADE POSSÍVEL: A ADMINISTRAÇÃO PÚBLICA COMO \\ PARTE NOS MECANISMOS ALTERNATIVOS DE SOLUÇÃO DE \\ CONTROVÉRSIAS ${ }^{1}$
}

\section{THE POSSIBLE CONFIDENTIALITY: THE PUBLIC ADMINISTRATION AS \\ PARTY IN THE ALTERNATIVE DISPUTE RESOLUTION MECHANISM}

Carlos Alberto de Salles

Professor Associado do Departamento de Direito Processual da USP. Livre docente, doutor e mestre pela USP. Desembargador do Tribunal de Justiça do Estado de São Paulo.

carlos.salles1407@gmail.com

RESUMO: Este artigo discute a tensão existente entre a confidencialidade, usual em mecanismos alternativos de solução de controvérsias, e o princípio da publicidade, que rege a Administração Pública no Brasil. Como solução aponta que o parâmetro para a confidencialidade envolvendo o Poder Público deve ser a preservação da accountability dos órgãos envolvidos, isto é, a capacidade de darem respostas a seus próprios objetivos e se submeterem ao controle público.

PALAVRAS-CHAVE: Mecanismos alternativos de solução de controvérsias, arbitragem, Administração Pública, confidencialidade, publicidade

ABSTRACT: This article debates the tension that exists between confidentiality, usual in ADRs, and the publicity principle, that rules the Public Administration in Brazil. As a solution points that the parameter of confidentiality when Public Administration is a party must be the preservation of accountability of the involved agencies, what means, the capacity to answer to its own goals and to obey the public control.

\footnotetext{
${ }^{1}$ Artigo recebido em 13/02/2017 e aprovado em 27/03/2017.
} 
Revista Eletrônica de Direito Processual - REDP.

Rio de Janeiro. Ano 11. Volume 18. Número 1. Janeiro a Abril de 2017

Periódico Quadrimestral da Pós-Graduação Stricto Sensu em Direito Processual da UERJ

Patrono: José Carlos Barbosa Moreira. ISSN 1982-7636. pp. 156-173

www.redp.uerj.br

KEYWORDS: ADRs mechanisms, arbitration, Public Administration, confidentiality, publicness

SUMÁRIO: 1. Introdução; 2. A confidencialidade na solução de controvérsias; 3. A confidencialidade nos mecanismos consensuais versus publicidade na Administração; 4. A confidencialidade na arbitragem; 5. O regime constitucional da publicidade no Judiciário e na Administração Pública; 6. A publicidade nos mecanismos extrajudiciais de solução de controvérsias; 7. Informação e accountability. 8. Conclusão.

\section{Introdução}

A utilização de mecanismos alternativos de solução de controvérsias pela Administração Pública ainda não está isenta de perplexidades e controvérsias. ${ }^{2}$ Afinal, não são poucos os pontos nos quais a possibilidade de utilização daqueles mecanismos põe em xeque o modo convencional de a Administração relacionar-se com o particular, especialmente em matéria contratual. ${ }^{3}$

Uma das principais questões levantadas diz respeito à confidencialidade, normalmente presente nos mecanismos extrajudiciais de solução de controvérsias. Diante do dever de publicidade, elevado à condição de princípio constitucional da Administração (artigo 37, caput, da Constituição Federal), parece estar inviabilizado, inteiramente, qualquer procedimento envolvendo algum grau de sigilo em seu iter.

\footnotetext{
${ }^{2}$ As reflexões abaixo complementam as ideias desenvolvidas pelo autor em publicação anterior: SALLES, Carlos Alberto de. Arbitragem em contratos administrativos. Rio de Janeiro: Forense, 2011. Nessa obra, discute o cabimento da arbitragem para solução de conflitos envolvendo a Administração, mas conclui, também, pela possibilidade e conveniência de por outros mecanismos, não-judiciais, serem utilizados vantajosamente pelo Poder Público.

${ }^{3}$ A esse respeito, cf. SALLES, op. cit., especialmente, o Capítulo 2, da Parte II (sustentando que conflitos envolvendo o Poder Público tendem a ser pouco considerados, em razão de posicionamentos afirmativos da supremacia da Administração em sua relação com particulares. Se efetivamente existente tal supremacia, de fato, não faz sentido falar-se em conflito administrativo, pois haveria sempre a submissão do particular ao interesse da Administração. Não é, no entanto, o que se verifica na realidade prática e jurídica. O resultado das posturas de supremacia da Administração é levar toda controvérsia administrativa à discussão judicial, sem que o Poder Público mobilize recursos para seu tratamento direto, mais rápido e eficiente).
} 
Revista Eletrônica de Direito Processual - REDP.

Rio de Janeiro. Ano 11. Volume 18. Número 1. Janeiro a Abril de 2017

Periódico Quadrimestral da Pós-Graduação Stricto Sensu em Direito Processual da UERJ

Patrono: José Carlos Barbosa Moreira. ISSN 1982-7636. pp. 156-173

www.redp.uerj.br

O presente artigo busca, em primeiro lugar, demonstrar de que maneira e por qual razão o sigilo, em algumas situações, mostra-se útil ao funcionamento na solução de disputas. Depois, busca discutir a possibilidade e os limites do envolvimento da Administração em procedimentos total ou parcialmente confidenciais, investigando, para tanto, o sentido a ser dado à publicidade em sua disciplina constitucional.

\section{A confidencialidade na solução de controvérsias versus publicidade na}

\section{Administração}

A confidencialidade tem sido uma característica verdadeiramente estruturante dos mecanismos consensuais e uma das principais vantagens atribuída à arbitragem como método adjudicatório de solução de controvérsias. ${ }^{4}$ Por meio dela se constrói a confiança das partes, deixando-as seguras de que não sofrerão consequências decorrentes de suas afirmações, propostas ou alegações utilizadas no desenvolvimento de qualquer desses mecanismos. ${ }^{5}$

O problema é que, em sentido contrário, a divulgação de dados e informações públicas é uma necessidade do Estado contemporâneo, exatamente por garantir as condições de accountability (responsividade) dos órgãos públicos, com discutido adiante.

Coloca-se, então, a necessidade de compatibilização dessas necessidades guiadas por vetores opostos.

Nos itens seguintes, busca-se delinear, primeiro, o papel da confidencialidade nos mecanismos de solução de controvérsia. Depois, procura-se entender o significado e

\footnotetext{
${ }^{4}$ Em interessante comparação entre as cortes estatais, tendentes à ampla publicidade, de forma a garantir "sunshine in litigation", nos moldes colocados pela autora, e os mecanismos não estatais, tendentes ao segredo, cf. DORE, Laurie Kratky. Public courts versus private justice: it's time to let some sun shine in on alternative dispute resolution. Chicago-Kent Law Review, vol. 81 (2006), p. 463/520.

${ }^{5}$ Cf. ARNAVAS, Don. Alternative dispute resolution for government contracts. Chicago: $\mathrm{CCH}, 2004, \mathrm{p}$. 36/37 (sustentando que a confidencialidade é parte da "mercadoria" oferecida por mecanismos como a mediação e a arbitragem).
} 
Revista Eletrônica de Direito Processual - REDP.

Rio de Janeiro. Ano 11. Volume 18. Número 1. Janeiro a Abril de 2017

Periódico Quadrimestral da Pós-Graduação Stricto Sensu em Direito Processual da UERJ

Patrono: José Carlos Barbosa Moreira. ISSN 1982-7636. pp. 156-173

www.redp.uerj.br

alcance da exigência constitucional de publicidade, encerrando-se com uma proposta de conciliação entre essas exigências aparentemente contraditórias.

\section{A confidencialidade nos mecanismos consensuais}

Os mecanismos consensuais, isto é, aqueles cuja solução do litígio é alcançada por meio de um acordo de vontade entre as partes, são métodos de soluções de controvérsias, baseados, sobretudo, em técnicas de facilitação da comunicação entre os sujeitos em disputa. Tais métodos são ministrados por um terceiro em posição de neutralidade ${ }^{6} \mathrm{em}$ relação aos envolvidos. O principal mecanismo dessa natureza e do qual partem diversas variações é a mediação. ${ }^{7}$

Além da característica de utilizar um terceiro em posição de equidistância entre as partes e de buscar um saldo positivo em sua comunicação, outros fatores são, também, fundamentais a sua caracterização. Esses fatores são o incentivo à troca de informações, o favorecimento ao entendimento recíproco das posições e interesses entre as partes, além da exploração de soluções criativas. ${ }^{8}$

\footnotetext{
${ }^{6}$ Afirmando que neutralidade, enquanto conjunto de condições aptas a garantir uma posição de equidistância em relação às partes, é o fator garantidor da imparcialidade e independência do terceiro em relação a uma controvérsia, v. SALLES, Carlos Alberto de. op. cit., p. 50/52.

${ }^{7}$ Embora a literatura brasileira acerca da mediação seja crescente, não há propriamente um consenso sobre quais sejam seus elementos definidores. Cf., a esse propósito, SAMPAIO, Lia Regina Castaldi; BRAGA NTO, Adolfo. O que é mediação de conflitos. São Paulo: Brasiliense, 2007, p. 19/22 (definindo a mediação como o método de resolução de conflitos em que um terceiro independente e imparcial busca estimular o diálogo cooperativo entre as partes para que alcancem uma solução das controvérsias); em sentido semelhante, cf. DEMARCHI, Juliana. Mediação: proposta de implementação no processo civil brasileiro. Tese (Doutorado em Direito) - Faculdade Direito, Universidade de São Paulo, São Paulo, 2007, p. 110/111 (para quem "mediação é um método de solução de conflitos que procura principalmente auxiliar as partes no atingimento de condições propícias para a negociação", p. 110). Valorizando a atividade como fator de definição, v. TARTUCE, Fernanda. Mediação nos conflitos civis. Rio de Janeiro: Método, 2008, p. 208 ("a mediação consiste na atividade de facilitar a comunicação entre as partes"); também CALMON, Petrônio. Fundamentos da mediação e da conciliação. Rio de Janeiro: Forense, 2007, p. 119 ("à inclusão informal ou formal de terceiro imparcial na negociação ou na disputa dá-se o nome de mediação"). Enfatizando o diálogo como instrumento central pelo qual se pode "ajudar os participantes a encontrar seu itinerário, na própria solução do conflito", cf. SCHNITMAN, Dora Fried. A mediação: novos desenvolvimentos geradores. In SCHNITMAN, Dora Fried e LITTLEJOHN, Stephen. Novos paradigmas em mediação. Porto Alegre: Artes Médicas Sul, 1999, p. 106.

${ }^{8}$ Nesse sentido, cf. KOVACH, Kimberlee K. Mediation. In MOFFITT, Michael L; BORDONE, Robert C. The handbook of dispute resolution. San Francisco: Jossey-Bass, 2005, p. 304. Para uma descrição e discussão das várias técnicas de mediação, v. RISKIN, Leonard L. Compreendendo as orientações, estratégias e técnicas do mediador: um padrão para perplexos. In: AZEVEDO, André Gomma de (org.). Estudos em arbitragem, mediação e negociação. - Brasília: Brasília Jurídica, 2002, p. 13/57. Para uma
} 
Revista Eletrônica de Direito Processual - REDP.

Rio de Janeiro. Ano 11. Volume 18. Número 1. Janeiro a Abril de 2017

Periódico Quadrimestral da Pós-Graduação Stricto Sensu em Direito Processual da UERJ

Patrono: José Carlos Barbosa Moreira. ISSN 1982-7636. pp. 156-173

www.redp.uerj.br

A esses fatores devem-se acrescentar dois importantes pressupostos, essenciais ao seu bom funcionamento: a confidencialidade e a predisposição de meios para favorecer a correta percepção do conflito e das possibilidades de sua solução. ${ }^{9}$

O sigilo das informações trazidas para a mediação pelas partes, inclusive quanto às suas expectativas, é condicionante da confiança dos participantes. ${ }^{10}$ Como ocorre em relação a todos os métodos consensuais de solução de controvérsias, ${ }^{11}$ a solução na mediação, também, não é dotada de compulsoriedade, isto é, pode ou não alcançar um resultado positivo. Dessa maneira, enquanto não concluída satisfatoriamente, com um acordo, há possibilidade de o litígio vir a ser levado a um meio adversarial de resolução, como o processo judicial ou a arbitragem. Para os mecanismos consensuais funcionarem a contento, portanto, as informações divulgadas no seu curso devem ser confidenciais, para não serem utilizadas, garantindo, com isso a confiança dos envolvidos.

Evidentemente, o sigilo da mediação ou de outros congêneres atinge àquelas provas apresentadas em seu procedimento, bem como os registros que deles tenham sido feitos, mas não torna sigilosa aquela prova apta a ser apresentada ou mesmo requerida em juízo. ${ }^{12}$ Caso contrário, esse mecanismo poderia ser utilizado para afastar uma prova de posterior conhecimento judicial.

Importante, de toda a maneira, são as ofertas e eventuais compromissos intermediários, feitos pelas partes, não fazerem prova de sua responsabilidade. ${ }^{13}$ Eventual

descrição das principais "escolas de mediação", v. DEMARCHI, op. cit., p. 111/127 (segundo a autora, seriam: o modelo de Harvard, mediação transformativa, modelo circular narrativo e mediação avaliativa).

${ }^{9}$ Sobre a percepção do conflito, cf. SALLES, op. cit., p. 181/182.

${ }^{10}$ Nos Estados Unidos vários instrumentos legais protegem a confidencialidade da mediação. A Federal Rules of Evidence, regras 408 e 501, estabelecem que as propostas ou compromissos não servem como admissão de responsabilidade e estabelece condições para que se possa testemunhar acerca de fatos ligados a uma mediação. Também o Uniform Mediation Act, de 2001, estabelece como confidencial qualquer comunicação ocorrida durante uma mediação. Cf. ARNAVAS, op. cit., p. 18/19. Também o ADRA, discutido no Capítulo anterior, em especial no Item 1.3.3., disciplina a confidencialidade nos ADRs utilizados na Administração Pública norte-americana.

${ }^{11}$ Destacando a importância do sigilo na mediação, cf. KOVACH, op. cit., p. 304/317, p. 312/313 e CALMON, op. cit., p. 121/122.

${ }^{12}$ Nesse sentido, SENGER, Jeffrey M. Federal dispute resolution: using ADR with the United States government. San Francisco: Jossey-Bass, 2004, p. 72/73.

${ }^{13}$ Nos termos do que garante a Regra 408 da Federal Rules of EvidenceI, nos Estados Unidos. 
Revista Eletrônica de Direito Processual - REDP.

Rio de Janeiro. Ano 11. Volume 18. Número 1. Janeiro a Abril de 2017

Periódico Quadrimestral da Pós-Graduação Stricto Sensu em Direito Processual da UERJ

Patrono: José Carlos Barbosa Moreira. ISSN 1982-7636. pp. 156-173

www.redp.uerj.br

testemunho do mediador fica, também, prejudicado, devendo-se reconhecer seu direito a sigilo profissional.

Sem mínimas garantias de sigilo quanto ao desenvolvimento dos procedimentos de composição amigável entre as partes, é difícil vislumbrar a possibilidade de seu efetivo engajamento na solução da disputa pendente entre elas. Afinal, se for diferente, sua atuação presente poderia comprometer estratégias futuras em um embate no Judiciário.

\section{A confidencialidade na arbitragem}

A Lei Brasileira de Arbitragem (Lei 9.307/96) não determina confidencialidade. Esse atributo, se desejável, é estabelecido pelas partes na convenção ou ao indicarem alguma instituição arbitral que traga esse requisito em seu regulamento. ${ }^{14}$

A confidencialidade, no caso da arbitragem, pode ter vários graus e, também, variável extensão, dependendo da vontade das partes. Pode dizer respeito à própria existência do processo arbitral, de seu resultado, de documentos ou informações especificadas e atuar em relação a determinadas pessoas, situações, entidades ou instituições. Em geral, no entanto, esse atributo é genericamente relacionado aos procedimentos da arbitragem.

A preferência por procedimentos sigilosos entre particulares é facilmente compreensível. Visam a preservar as partes e seus interesses do conhecimento público. A existência de uma disputa e a divulgação de suas peculiaridades pode atingir a reputação de uma pessoa ou empresa e prejudicar-lhe os negócios. Convém, portanto, mantê-la fora do conhecimento geral, impedir que uma desavença, muitas vezes pontual, tenha repercussão negativa sobre os interesses envolvidos.

\footnotetext{
${ }^{14}$ Em geral, os centros e câmaras de arbitragem trazem cláusula de confidencialidade. V. os regulamentos da Câmara de Comércio Brasil-Canadá, seção 9, itens 9.8 e 9.9, da Câmara do Instituto Brasileiro de Estudos do Direito da Energia, art. 79, da Câmara Fundação Getúlio Vargas de Conciliação e Arbitragem, art. 61, Câmara de Mediação e Arbitragem de São Paulo - CIESP, item 17.4, Centro de Arbitragem da Câmara Americana de Comércio de São Paulo, item XXV.1.
} 
Revista Eletrônica de Direito Processual - REDP.

Rio de Janeiro. Ano 11. Volume 18. Número 1. Janeiro a Abril de 2017

Periódico Quadrimestral da Pós-Graduação Stricto Sensu em Direito Processual da UERJ

Patrono: José Carlos Barbosa Moreira. ISSN 1982-7636. pp. 156-173

www.redp.uerj.br

Por todas essas razões a confidencialidade tem prevalecido nas práticas arbitrais, não obstante não haja disposição legal impondo esse requisito.

Quando se cuida de utilizar a arbitragem para solução de controvérsias às quais está ligada a Administração Pública, no entanto, é preciso algum cuidado com esse valor central das arbitragens em relações privadas. Isso porque a publicidade dos atos da administração pública vem se colocando como um dos princípios centrais da atividade administrativa contemporânea, como garantidora da transparência $^{15}$ dos atos da administração e da responsividade ${ }^{16}$ dos agentes públicos.

Este trabalho sustenta, entretanto, como desenvolvido a seguir, a possibilidade de o sigilo ser graduado e regulado no procedimento arbitral, de forma a atender o requisito de publicidade, desde que garanta informação suficiente à responsividade procedimental, sem comprometer as qualidades do processo arbitral.

\section{O regime constitucional da publicidade no Judiciário e na Administração Pública}

A publicidade é colocada pela Constituição Federal em termos amplos: "a lei só poderá restringir a publicidade dos atos processuais quando a defesa da intimidade ou o interesse social o exigirem" (artigo $5^{\circ}$, inciso LX). Ainda mais, condiciona o exercício da atividade jurisdicional do Estado a julgamentos públicos, permitindo limitações “nos casos nos quais a preservação do direito à intimidade do interessado no sigilo não prejudique o interesse público à informação" (artigo 93, inciso IX).

\footnotetext{
${ }^{15}$ A Portaria Interministerial 140, de 16.03.2006, estabelece que os órgãos públicos deverão disponibilizar na internet as informações básicas sobre sua execução de seu orçamento. Dispõe seu art. $2^{\circ}$ : "Art. $2^{\circ}$ Os órgãos e entidades da Administração Pública Federal deverão manter em seus respectivos sítios eletrônicos na rede mundial de computadores página denominada 'Transparência Pública', tendo por conteúdo mínimo as informações previstas nesta Portaria".

${ }^{16}$ Traduzindo o que vem sem denominado na literatura internacional por accountability, como indicado a seguir.
} 
Revista Eletrônica de Direito Processual - REDP.

Rio de Janeiro. Ano 11. Volume 18. Número 1. Janeiro a Abril de 2017

Periódico Quadrimestral da Pós-Graduação Stricto Sensu em Direito Processual da UERJ

Patrono: José Carlos Barbosa Moreira. ISSN 1982-7636. pp. 156-173

www.redp.uerj.br

Não obstante nenhum dos dois dispositivos permita um entendimento da publicidade em termos absolutos, não restam dúvidas, quanto à nítida opção constitucional por sua abrangência, em regra, a todos os atos administrativos e judiciais.

No que interessa ao tema em desenvolvimento, cabe discutir, diante das normas constitucionais, a possibilidade de confidencialidade em determinados mecanismos de solução de controvérsias - a arbitragem entre eles - dos quais a Administração participe. Para tanto, há de se discutir o significado e a extensão pretendida pelo texto constitucional em suas referências à publicidade.

A propósito, vale lembrar, ainda, que quanto à Administração Pública, a publicidade é constitucionalmente colocada entre os princípios a serem por ela obedecidos, ao lado da legalidade, da impessoalidade, da moralidade e da eficiência (artigo 37, caput, Constituição Federal).

Para entender o alcance da publicidade em sua colocação constitucional, em primeiro lugar, é importante estabelecer sua natureza de garantia, não propriamente de um direito constitucional, em razão das diferentes conclusões a que remetem os dois institutos.

Acerca desse ponto, cabe recordar que, na expressão de JOSÉ AFONSO DA SILVA, "direitos são bens e vantagens conferidos ela norma, enquanto as garantias são meios destinados a fazer valer esses direitos, são instrumentos pelos quais se asseguram o exercício e gozo daqueles bens e vantagens". ${ }^{17}$

Nesse sentido, a publicidade deve ser vista como uma maneira de garantir o devido processo legal, o contraditório, a ampla defesa e outros direitos processuais garantidos pela Constituição. ${ }^{18}$ Como se verifica, não trata, propriamente, de um "direito à publicidade",

${ }^{17}$ Curso de Direito Constitucional Positivo. São Paulo: Malheiros, 2011, p. 413. O autor esclarece que, não obstante conhecida posição de Rui Barbosa a esse respeito, a Constituição Federal "não separa rigorosamente os direitos de suas garantias. Houve várias propostas nesse sentido, mas o Relator, constituinte Bernardo Cabral, não teve a sensibilidade para uma sistematização constitucional que organizasse os direitos e suas garantias em capítulos separados" (p. 186, nota 36).

${ }^{18}$ Cf. GRECO FILHO, Vicente. Direito Processual Civil Brasileiro. 22a edição. São Paulo: Saraiva, 2010, p. 71; também MENDONÇA, Priscila Faricelli de. Notas sobre o princípio da publicidade processual na 
Revista Eletrônica de Direito Processual - REDP.

Rio de Janeiro. Ano 11. Volume 18. Número 1. Janeiro a Abril de 2017

Periódico Quadrimestral da Pós-Graduação Stricto Sensu em Direito Processual da UERJ

Patrono: José Carlos Barbosa Moreira. ISSN 1982-7636. pp. 156-173

www.redp.uerj.br

mas de garantir a observância de outros direitos, colocando o jurisdicionado ou o cidadão, por meio dela, livre de qualquer arbítrio no exercício do poder.

Aliás, a se considerar a publicidade como direito - fundamental em razão de sua ubiquação constitucional - qualquer limitação que se mostrasse estrutural ou funcionalmente necessária seria bastante mais complicada em termos jurídicos. ${ }^{19}$ Sendo garantia sua aplicação deve levar em conta sempre o direito a ser por ela protegido, ter em conta as finalidades às quais se destina, sem que se coloque como valor autônomo. Daí as possibilidades, assentes e tranquilas, de sua limitação, como aquelas do artigo 155 do Código de Processo Civil.

Mesmo a norma do artigo 37, caput, da Constituição Federal, muito embora textualmente indicada como princípio, deve ser entendida como exercendo uma na típica função de garantia. Sua finalidade, claramente, é a de assegurar o acesso ilimitado às informações relativas aos atos e atividades da Administração. Sob esse enfoque, também, a publicidade não vale por si mesma, mas como garantia de acesso a informações da Administração Pública.

A esse propósito, ainda com o objetivo de entender o exato alcance da garantia constitucional estudada, deve-se ter clara a centralidade da informação como objeto de proteção pela publicidade.

De maneira geral, pode-se dizer que a publicidade visa a garantir que toda informação envolvida em processos estatais, judiciais ou administrativos, tenha acesso

atualidade: processo eletrônico e mídia. In: Revista Dialética de Direito Processual, n. 101 (agosto - 2011), p. 117/118 (examinando a colisão dessa garantia com outras igualmente consagradas na Constituição Federal).

19 O STF admite limitações à publicidade, como demonstra o seguinte julgado: "Não se deu, no caso, qualquer violação dos princípios do contraditório e da ampla defesa (art. $5^{\circ}, \mathrm{LV}$, da CB) na auditoria que levou à instauração do processo administrativo disciplinar. O procedimento que antecedeu a instauração do PAD [Processo Administrativo Disciplinar], independentemente do nome que lhe seja dado, nada mais é do que uma sindicância, cujo objetivo é o de colher indícios sobre a existência da infração funcional e sua autoria. Trata-se de procedimento preparatório, não litigioso, em que o princípio da publicidade é atenuado." (MS 23.187, Rel. Min. Eros Grau, julgamento em 27-5-2010, Plenário, DJE de 6-8-2010) 
Revista Eletrônica de Direito Processual - REDP.

Rio de Janeiro. Ano 11. Volume 18. Número 1. Janeiro a Abril de 2017

Periódico Quadrimestral da Pós-Graduação Stricto Sensu em Direito Processual da UERJ

Patrono: José Carlos Barbosa Moreira. ISSN 1982-7636. pp. 156-173

www.redp.uerj.br

público. ${ }^{20}$ Ela, portanto, diz respeito às informações que as partes ou terceiros podem e devem ter acesso em um processo ou que o sujeito pode exigir em face da Administração, seja para fins de controle, seja para satisfação de seus interesses.

Entendida a publicidade dessa maneira, suas limitações, previstas em lei, apontam para exceções à regra de livre acesso às informações. Tais limitações se justificam por razões de proteção da intimidade ou do interesse social, exigindo que, em situações determinadas, o fluxo informacional deva ser restrito, por exemplo, às partes e ao juiz, ou a determinados órgãos, agentes públicos e interessados diretos.

Sob essa perspectiva, a disciplina constitucional da publicidade pode ser entendida como o controle jurídico da disponibilização das informações, públicas ou particulares, detidas por órgãos estatais. Nesse sentido, presta-se a indicar as situações nas quais as informações devem ser disponibilizadas para acesso público e aquelas sujeitas a algum grau de sigilo.

\section{A publicidade nos mecanismos extrajudiciais de solução de controvérsias}

A garantia de publicidade prevista constitucionalmente deve se projetar na arbitragem e em outros mecanismos extrajudiciais, quando estes tenham por objeto negócios do Estado. De fato, não é possível concebê-los como espaço isento dos controles próprios da Administração Pública.

\footnotetext{
${ }^{20}$ A ligação entre publicidade e informação fica evidente não apenas no inciso IX, do artigo 93, da Constituição Federal, ao admitir o sigilo apenas quanto "não prejudique o interesse público à informação", mas, também, na discussão jurisprudencial do tema, como demonstra o seguinte julgado do STF: A publicidade e o direito à informação não podem ser restringidos com base em atos de natureza discricionária, salvo quando justificados, em casos excepcionais, para a defesa da honra, da imagem e da intimidade de terceiros ou quando a medida for essencial para a proteção do interesse público. A coleta de dados históricos a partir de documentos públicos e registros fonográficos, mesmo que para fins particulares, constitui-se em motivação legítima a garantir o acesso a tais informações. No caso, tratava-se da busca por fontes a subsidiar elaboração de livro (em homenagem a advogados defensores de acusados de crimes políticos durante determinada época) a partir dos registros documentais e fonográficos de sessões de julgamento público. Não configuração de situação excepcional a limitar a incidência da publicidade dos documentos públicos (arts. 23 e 24 da Lei 8.159/1991) e do direito à informação." (RMS 23.036, Rel. p/ o ac. Min. Nelson Jobim, julgamento em 28-3-2006, Segunda Turma, $D J$ de 25-8-2006)
} 
Revista Eletrônica de Direito Processual - REDP.

Rio de Janeiro. Ano 11. Volume 18. Número 1. Janeiro a Abril de 2017

Periódico Quadrimestral da Pós-Graduação Stricto Sensu em Direito Processual da UERJ

Patrono: José Carlos Barbosa Moreira. ISSN 1982-7636. pp. 156-173

www.redp.uerj.br

Resta saber qual o significado concreto a ser dado a essa garantia, isto é, quais atos do procedimento arbitral ou etapas de um procedimento consensual a ela se submeteriam, de maneira a não descaracterizar esses mecanismos extrajudiciais com a imposição de formalidades impróprias a seu desenvolvimento.

A esse propósito, deve-se ter clara a existência de variáveis de graus de sigilo, dependendo os atos ou fases procedimentais sobre os quais ele recaia. É possível, por exemplo, que a confidencialidade diga respeito a apenas uma parcela de todo o procedimento envolvido ou a algumas das informações nele constantes. ${ }^{21}$

Para garantir o controle desejado pela própria Constituição e, ao mesmo tempo, manter o sigilo quando necessário ao funcionamento dos mecanismos alternativos de solução de controvérsias é fundamental garantir pelo menos a disponibilização de informações quanto à sua existência e, posteriormente, quanto a seus resultados.

Na arbitragem envolvendo o Poder Público, por exemplo, é fundamental a ampla publicidade da sentença arbitral e dos documentos produzidos durante o procedimento arbitral. Nesse sentido, acredita-se ser essencial a divulgação, também, dos elementos de prova e de argumentação que serviram de base à decisão da arbitragem.

Nos Estados Unidos, há a obrigação legal de divulgação da decisão proferida, como, ademais de toda decisão administrativa. ${ }^{22} \mathrm{O}$ Freedom of Information Act - FOIA estabeleceu uma série de medidas para garantir a publicidade e a acessibilidade de dados da Administração Pública. ${ }^{23}$ As previsões desse diploma legal precisam ser compatibilizadas com aquelas do Administrative Dispute Resolution Act - ADRA, que traz

\footnotetext{
${ }^{21}$ É a conclusão que, analogamente, chegou o STF ao discutir o sigilo das votações do Tribunal do Júri, admitindo que o sigilo desse iter procedimental não fere a garantia de publicidade, presento no restante procedimento: "Tribunal do Júri. Sigilo das votações (art. $5^{\circ}$, XXXVIII, CF) e publicidade dos julgamentos (art. 93, IX, CF). Conflito aparente de normas. Distinção entre julgamento do Tribunal do Júri e decisão do Conselho de Jurados. Manutenção pelo sistema constitucional vigente do sigilo das votações, através de disposição específica." (RE 140.975-AgR, Rel. Min. Paulo Brossard, julgamento em 23-6-1992, Segunda Turma, $D J$ de 21-8-1992)

225 USCS § 552 (a) (2) (A).

${ }^{23}$ Cf. Item 1.3.3., do Capítulo 1, da Parte III, acima.
} 
Revista Eletrônica de Direito Processual - REDP.

Rio de Janeiro. Ano 11. Volume 18. Número 1. Janeiro a Abril de 2017

Periódico Quadrimestral da Pós-Graduação Stricto Sensu em Direito Processual da UERJ

Patrono: José Carlos Barbosa Moreira. ISSN 1982-7636. pp. 156-173

www.redp.uerj.br

toda uma seção acerca da confidencialidade dos procedimentos nele previstos. ${ }^{24}$ Os procedimentos arbitrais, no entanto, não foram abrangidos pelas disposições gerais de sigilo dessa última lei, podendo este ser estabelecido por via convencional, desde que não alcance a sentença arbitral, cuja publicidade não pode ser afastada por força do FOIA. ${ }^{25}$

No caso brasileiro, a exclusiva divulgação da sentença, sem os elementos que the serviram de base, pode, ao contrário de preservar o modo arbitral de solução de controvérsias, acabar por fragilizar a própria sentença. Por essa razão, acredita-se necessária a divulgação da documentação apresentada e formada durante o processo arbitral. Essa última contribuiria para a estabilidade e legitimidade da sentença arbitral, ao permitir uma completa demonstração de seus fundamentos.

Destaque-se que alternativas, conquanto que ampliativas da publicidade, poderão ser validamente adotadas pelo Administrador na regulamentação, na convenção arbitral ou no edital do procedimento no qual se pretenda utilizar mecanismos extrajudiciais de solução de controvérsias.

\section{Informação e accountability}

De maneira geral, pode-se dizer que os requisitos a serem atendidos, para adequação de mecanismos alternativos de solução de controvérsias à participação da Administração Pública, podem ser resumidos àqueles necessários para garantir responsividade, isto é, aquele elemento designado na literatura de língua inglesa por accountability, indicativo de que qualquer atividade estatal deve estar submetida a controles públicos, tanto internos quanto externos à Administração. ${ }^{26}$

O conceito de accountability deriva do francês antigo, falado nas cortes inglesas em seus primórdios, significando o equivalente a comptes a rendre, isto é, rendering of

\footnotetext{
$24 \S 574$.

$25 \S 552$ (a) (2) (A). Cf. DEPARTMENT OF JUSICE. Phyllis Hanfling, Department of Energy, e Martha McClellan, Federal Deposit Insurance Corporation. Developing guidance for binding arbitration: a Handbook for Federal Agencie. Disponível em http://www.justice.gov/adr/arbitra.htm. Acesso em 19/07/2010, component 2 (Administered Arbitration) e, também, issues 1 e 17.

${ }^{26}$ Cf. SALLES, op. cit., p. 79/82.
} 
Revista Eletrônica de Direito Processual - REDP.

Rio de Janeiro. Ano 11. Volume 18. Número 1. Janeiro a Abril de 2017

Periódico Quadrimestral da Pós-Graduação Stricto Sensu em Direito Processual da UERJ

Patrono: José Carlos Barbosa Moreira. ISSN 1982-7636. pp. 156-173

www.redp.uerj.br

accounts ou prestação de contas. ${ }^{27} \mathrm{~A}$ tradução para o vernáculo tem sido feita, muitas

vezes como "responsabilidade" 28 ou "responsividade" 29 . Considerando que a primeira remete a um conceito jurídico específico, relacionado à aplicação de uma sanção jurídica, daí a responsabilidade penal, civil ou administrativa, prefere-se o segundo, responsividade, pelo fato de nem sempre o este conceito implicar a um sancionamento jurídico.

De fato, accountability ou responsividade indica uma série de respostas esperadas dos agentes e instituições públicas, sem significar, necessariamente a aplicação de uma sanção jurídica. ${ }^{30}$

Importante delimitação ao conceito de responsividade deve ser tributada a Guilhermo O'Donnell ao distingui-la em horizontal e vertical. ${ }^{31}$ Partindo da premissa de que, nas democracias representativas contemporâneas, a eleição serve como um instrumento de controle, pelo qual o eleitor aprova ou condena a gestão do político eleito para o mandato a ela antecedente, a responsividade vertical indica esse controle democrático exercido pela relação eleitor/político eleito. ${ }^{32}$ A horizontal diz respeito à existência de órgãos estatais competentes e capacitados para realizar uma variada gama de atividades de supervisão, da imposição de sanções penais à simples controles políticos, como aquele do legislativo em relação ao gabinete no regime parlamentarista. ${ }^{33}$

${ }^{27} \mathrm{Cf}$. KEOHANE, Robert O. The concept of accountability in world politics and the use of force. Michigan Journal of International Law, n. 24 (Summer 2003), p. 1.123/1.124

28 V. BRESSER PEREIRA, Luiz Carlos; CUNILL GRAU, Nuria (Coord.). Responsabilização na administração pública. São Paulo: CLAD/Fundap, 2006.

${ }^{29}$ V. FARIA, José Eduardo. Direito e economia na democratização brasileira. São Paulo: Malheiros, 1993 , p. 30 e 135. Destacando uma concepção de direito responsivo, no sentido de uma ordem legal mais aberta às influências sociais, a partir das idéias de Selznick e Nonet, v. CAMPILONGO, Celso Fernandes. Direito e democracia. São Paulo: Max Limonad, 1997, p. 58/65.

30 "Eu delimito o conceito de accountability política à relação que formalmente dão a algum ator a autoridade de supervisão e/ou sancionamento relativo a agentes públicos." MAINWARING, Scott. Introduction: democratic accountability in Latin America. In: MAINWARING, Scott. E WELNA, Christopher. Democratic accountability in Latin America. Oxford/New York: Oxford University, 2003, p. 7, traduzido do original.

31 CF. O'DONNELL, Guilhermo. Horizontal accountability: the legal institutionalization of mistrust. In MAINWARING, Scott. E WELNA, Christopher. Democratic accountability in Latin America. Oxford/New York: Oxford University, 2003, p. 34/54 (retomando os conceitos propostos em obra anterior de 1999).

${ }^{32}$ A propósito, retomar os conceitos de principal e agent, destacado no item 3.1.4., deste capítulo, acima.

${ }^{33}$ Cf. MAINWARING, op. cit., p. 10/12 (objetando que a accountability horizontal não pode ficar limitada àquelas situações em que haja transgressão legal). O’Donnel define responsividade horizontal como "a existência de agências estatais que são legalmente capacitadas e dotadas de poder, além de factualmente desejosas e aptas, para empreender ações que vão de rotineira supervisão a sanções criminais ou 
Revista Eletrônica de Direito Processual - REDP.

Rio de Janeiro. Ano 11. Volume 18. Número 1. Janeiro a Abril de 2017

Periódico Quadrimestral da Pós-Graduação Stricto Sensu em Direito Processual da UERJ

Patrono: José Carlos Barbosa Moreira. ISSN 1982-7636. pp. 156-173

www.redp.uerj.br

No caso, a publicidade é o principal instrumento para garantir a responsividade dos agentes públicos envolvidos em mecanismos extrajudiciais para solução de controvérsias administrativas. Publicidade deve ser entendida, nos temos indicados acima, como garantia de acessibilidade à informação relativa ao funcionamento e ao resultado desses mecanismos.

É importante, nesse contexto, ter presente que, no Brasil, o controle da Administração Pública é feito por vários instrumentos, entidades e sujeitos não necessariamente coordenados.

Em primeiro lugar, a administração está submetida à responsividade vertical, quer dizer por parte do eleitor. Submete-se, também, àquela horizontal, realizada por uma pluralidade de órgãos de controle, internos ou autônomos, tais como corregedorias ou controladorias, Tribunais de Contas e Ministério Público.

Além desses controles, os atos da Administração estão submetidos a mecanismos de participação verdadeiramente societais, quer dizer, não representativos de outro órgão público, mas derivado da própria sociedade, através de mecanismos de participação ${ }^{34} \mathrm{e}$ da possibilidade de qualquer cidadão impugná-los por meio de uma ação popular. ${ }^{35}$

Para o funcionamento desse sistema de controles, ao qual certamente falta organicidade, um elemento fundamental vem a ser a difusão e acessibilidade de informações públicas, a que, grosso modo, poder-se-ia chamar de transparência administrativa. $^{36}$

impeachment, decorrentes de ações ou omissões de outros agentes ou agências do Estado que podem ser qualificadas como ilegais." O’DONNEL, Guilhermo. op. cit., p. 34.

${ }^{34}$ Cf. MATTOS, Paulo Todescan Lessa. O novo Estado regulador no Brasil: eficiência e legitimidade. São Paulo: FAPESP/Singular, 2006, p. 247/286 (estudando os mecanismos de participação pública no setor de Telecomunicações).

${ }^{35}$ Destacando o papel democrático da ação popular, cf. GOMES FILHO, Antonio Magalhães. Ações Populares e participação política. In: GRINOVER, Ada Pellegrini; DINAMARCO, Cândido Rangel; WATANABE, Kazuo. Participação e processo. São Paulo: RT, 1988, p. 180/189.

36 Sobre esse conceito e suas implicações, v. MARTINS JÚNIOR, Wallace Paiva. Transparência administrativa - publicidade, motivação e participação popular. São Paulo: Saraiva, 2004. 
Revista Eletrônica de Direito Processual - REDP.

Rio de Janeiro. Ano 11. Volume 18. Número 1. Janeiro a Abril de 2017

Periódico Quadrimestral da Pós-Graduação Stricto Sensu em Direito Processual da UERJ

Patrono: José Carlos Barbosa Moreira. ISSN 1982-7636. pp. 156-173

www.redp.uerj.br

Em especial quanto à arbitragem, que surge e se desenvolve em um ambiente

privado, tendente ao sigilo e ao isolamento do seu procedimento, o procedimento arbitral deve ser especialmente dotado de regras garantidoras da adequada disponibilização de informações, de forma a propiciar a sobredita responsividade. Para tanto, deve-se promover uma adequada e suficiente disponibilização de informação.

A confidencialidade, na extensão adotada em arbitragens e outros mecanismos alternativos privados, não é possível em relação à administração pública, exatamente pela necessidade de controle em qualquer uma das modalidades apontadas acima.

A disponibilidade e acessibilidade da informação aparecem, nesse sentido, como requisitos centrais para o funcionamento do controle do Poder Público.

Isso não quer dizer, entretanto, que o processo arbitral e outros métodos de solução de disputas devam submeter-se ao mesmo regime de publicidade de nosso processo civil. Nada impede, por razões de praticidade, que os procedimentos ou parte deles sejam sigilosos, devendo-se, entretanto, garantir-se a publicidade da sentença e das provas produzidas, como já sustentado.

\section{Conclusão}

A utilização de mecanismos alternativos de solução de controvérsias no âmbito da Administração Pública exige adaptações, para que esses meios, concebidos para o tratamento de interesses privados, possam atender àqueles parâmetros próprios da disciplina jurídica do Poder Público.

Por certo, o principal campo de embates entre os modos usuais de funcionamento desses mecanismos e a disciplina da Administração é, exatamente, aquele da publicidade. Isso porque os chamados mecanismos consensuais usam a confidencialidade como um elemento chave conquistar a confiança das partes, facilitar sua comunicação e atingir um acordo. Também a arbitragem, mesmo não tendo o sigilo como imposição legal, tem sua prática fortemente sedimentada em procedimentos confidenciais. 
Revista Eletrônica de Direito Processual - REDP.

Rio de Janeiro. Ano 11. Volume 18. Número 1. Janeiro a Abril de 2017

Periódico Quadrimestral da Pós-Graduação Stricto Sensu em Direito Processual da UERJ

Patrono: José Carlos Barbosa Moreira. ISSN 1982-7636. pp. 156-173

www.redp.uerj.br

Dessa maneira, as exigências constitucionais de publicidade devem ser compatibilizadas quando referidos mecanismos tiverem a Administração como parte.

Assim, deve-se pensar naquela confidencialidade possível, como destaca o título do presente trabalho, de forma a não desestruturar aqueles métodos alternativos e, ao mesmo tempo, atende à exigência de publicidade nos negócios do Estado. O sigilo, de todo modo, deve sempre ser a exceção.

Como desenvolvido acima, os limites dessa possibilidade estão situados na garantia de acesso àquelas informações básicas, necessárias a permitir o controle público e gerar a responsividade dos agentes públicos envolvidos. Nesse sentido, a manutenção de determinados atos ou etapas procedimentais confidenciais não fere a garantia constitucional de publicidade, desde que garantida a disponibilidade das informações necessárias ao controle dos atos e atividades do Poder Público.

\section{REFERÊNCIAS BIBLIOGRÁFICAS}

ARNAVAS, Don. Alternative dispute resolution for government contracts. Chicago: $\mathrm{CCH}$, 2004.

BRESSER PEREIRA, Luiz Carlos e CUNILL GRAU, Nuria (Coord.). Responsabilização na administração pública. São Paulo: CLAD/Fundap, 2006.

CALMON, Petrônio. Fundamentos da mediação e da conciliação. Rio de Janeiro: Forense, 2007.

CAMPILONGO, Celso Fernandes. Direito e democracia. São Paulo: Max Limonad, 1997.

DEMARCHI, Juliana. Mediação: proposta de implementação no processo civil brasileiro.

Tese (Doutorado em Direito) - Faculdade Direito, Universidade de São Paulo, São Paulo, 2007.

DEPARTMENT OF JUSICE. Phyllis Hanfling, Department of Energy, e Martha McClellan, Federal Deposit Insurance Corporation. Developing guidance for binding arbitration: a Handbook for Federal Agencie. Disponível em 
Revista Eletrônica de Direito Processual - REDP.

Rio de Janeiro. Ano 11. Volume 18. Número 1. Janeiro a Abril de 2017

Periódico Quadrimestral da Pós-Graduação Stricto Sensu em Direito Processual da UERJ

Patrono: José Carlos Barbosa Moreira. ISSN 1982-7636. pp. 156-173

www.redp.uerj.br

http://www.justice.gov/adr/arbitra.htm. Acesso em 19/07/2010, component 2

(Administered Arbitration) e, também, issues 1 e 17.

DORE, Laurie Kratky. Public courts versus private justice: it's time to let some sun shine in on alternative dispute resolution. Chicago-Kent Law Review, vol. 81 (2006), p. $463 / 520$.

FARIA, José Eduardo. Direito e economia na democratização brasileira. São Paulo: Malheiros, 1993.

GOMES FILHO, Antonio Magalhães. Ações Populares e participação política. In GRINOVER, Ada Pellegrini, DINAMARCO, Cândido Rangel e WATANABE, Kazuo. Participação e processo. São Paulo: RT, 1988, p. 180/189.

GRECO FILHO, Vicente. Direito Processual Civil Brasileiro. 22a edição. São Paulo: Saraiva, 2010

KEOHANE, Robert O. The concept of accountability in world politics and the use of force. Michigan Journal of International Law, n. 24 (Summer 2003), p. 1.121/1.141.

KOVACH, Kimberlee K. Mediation. In MOFFITT, Michael L. e BORDONE, Robert C. The handbook of dispute resolution. San Francisco: Jossey-Bass, 2005

MAINWARING, Scott. E WELNA, Christopher. Democratic accountability in Latin America. Oxford/New York: Oxford University, 2003.

MARTINS JÚNIOR, Wallace Paiva. Transparência administrativa - publicidade, motivação e participação popular. São Paulo: Saraiva, 2004.

MATTOS, Paulo Todescan Lessa. O novo Estado regulador no Brasil: eficiência e legitimidade. São Paulo: FAPESP/Singular, 2006.

MENDONÇA, Priscila Faricelli de. Notas sobre o princípio da publicidade processual na atualidade: processo eletrônico e mídia. Revista Dialética de Direito Processual, n. 101 (agosto - 2011), p. 114/132.

O'DONNELL, Guilhermo. Horizontal accountability: the legal institutionalization of mistrust. In MAINWARING, Scott. E WELNA, Christopher. Democratic accountability in Latin America. Oxford/New York: Oxford University, 2003.

RISKIN, Leonard L. Compreendendo as orientações, estratégias e técnicas do mediador: um padrão para perplexos. In AZEVEDO, André Gomma de (org.). Estudos em arbitragem, mediação e negociação. - Brasília: Brasília Jurídica, 2002. 
Revista Eletrônica de Direito Processual - REDP.

Rio de Janeiro. Ano 11. Volume 18. Número 1. Janeiro a Abril de 2017

Periódico Quadrimestral da Pós-Graduação Stricto Sensu em Direito Processual da UERJ

Patrono: José Carlos Barbosa Moreira. ISSN 1982-7636. pp. 156-173

www.redp.uerj.br

SALLES, Carlos Alberto de. Arbitragem em contratos administrativos. Rio de Janeiro: Forense, 2011.

SAMPAIO, Lia Regina Castaldi e BRAGA NETO, Adolfo. O que é mediação de conflitos.

São Paulo: Brasiliense, 2007

SCHNITMAN, Dora Fried. A mediação: novos desenvolvimentos geradores. In SCHNITMAN, Dora Fried e LITTLEJOHN, Stephen. Novos paradigmas em mediação. Porto Alegre: Artes Médicas Sul, 1999.

SENGER, Jeffrey M. Federal dispute resolution: using ADR with the United States government. San Francisco: Jossey-Bass, 2004.

SILVA, José Afonso da. Curso de Direito Constitucional Positivo. São Paulo: Malheiros, 2011.

TARTUCE, Fernanda. Mediação nos conflitos civis. Rio de Janeiro: Método, 2008. 